\title{
Aflatoxin and Genetically Modified Organisms Analysis in Turkish Corn
}

\author{
Nevzat Artiki,2, Nevzat Konar ${ }^{3 *}$, Muhip Özkan4', M. Lütfü Çakmakçi1 \\ ${ }^{1}$ Food Engineering Department, Faculty of Engineering, Ankara University, Ankara, Turkey \\ ${ }^{2}$ Food Safety Institute, Ankara University, Ankara, Turkey \\ ${ }^{3}$ Food Engineering Department, Faculty of Engineering and Architecture, Siirt University, Siirt, Turkey \\ ${ }^{4}$ Faculty of Agriculture, Biometry and Genetic Sciences, Ankara University, Ankara, Turkey \\ Email: "nevzatkonar@hotmail.com
}

Received 24 December 2015; accepted 26 February 2016; published 29 February 2016

Copyright (C) 2016 by authors and Scientific Research Publishing Inc.

This work is licensed under the Creative Commons Attribution International License (CC BY).

http://creativecommons.org/licenses/by/4.0/

(c) (i) Open Access

\begin{abstract}
Genetically Modified Organisms (GMOs) are plants, animals or microorganisms that have been altered using genetic insertion or deletion via technology (also called genetic engineering or GE). Corn is one of the main inputs of both food and feed production. Also it is a major commodity of which many transgenic varieties are commercially available. In this study, the aflatoxin and GMO analyses of corn were made in two different years (2013 and 2014). Corn samples were collected between August and October in 2013 and 2014 around Turkey from non-neighboring fields representing each 10 thousand tons production and blending. After the analyses, which were performed by using LC-MS/MS technique, 38 of 538 corn samples (7.06\%) were found to contain aflatoxin in 2013. 17 of these were collected from the first harvest, 21 were from the second harvest period. Aflatoxin limits were exceeded in samples from only 2 regions in 2014. This study also reports results of GMO screening tests with $0.05 \%$ detection limit in two marketing years. 35D promoter, NOS terminator and FMV promoter are sought with the tests. None of the samples shows positive results, that is, samples do not contain GMO.
\end{abstract}

\section{Keywords}

Corn, Real Time PCR, GMO, Aflatoxin

\section{Introduction}

The use of biotechnology in the United States' agricultural industry in the 1990s, and then other countries,

${ }^{*}$ Corresponding author. 
enhanced seed production, which enabled the creation of such innovations as herbicide-tolerant seeds; these creations became known as genetically modified organisms (GMOs) [1]. However, food consumption is an important pathway of human exposure to pesticides and other chemical contaminants. Studies have shown that exposure to contaminants in food can pose a public health risk [2]. In recent years, a significant increase has been observed in the usage of foods containing genetically modified products. In order to protect biodiversity and to ensure conscious consumption, an analysis of GMOs and the processed foods in which GMOs are used as raw materials must be done and these products must be labeled [3].

GMOs are plants, animals or microorganisms that have been altered using genetic insertion or deletion via technology (also called genetic engineering or GE). Merged DNA from different species creates combinations of plant, animal, bacteria and/or virus genes that cannot occur in nature or in traditional crossbreeding [4]. However, technological advances have not been viewed as positive by all consumers. In particular, despite scientific evidence to the contrary, skepticism and suspicion regarding the safety and quality of GMOs exists among many consumers [5].

Corn (Zea mays) is a major commodity of which many transgenic varieties are commercially available [6]. Today corn occupies an important place in human nutrition around the world with its large economic value and high energy content. A grain of corn contains high amounts of carbohydrates (starch), protein, different sugar derivatives, fibers and oils as well as significant amounts of iron, magnesium, potassium, vitamins $A, B_{1}, B_{3}, B_{9}$ and C. Also, corn, soybean and cotton are genetically modified to express foreign proteins to manage lepidopteran insect pests or to allow application of herbicides (glyphosate and/glufosinate) to control weeds [7].

Corn, which is the most produced cereal in the world, has twice more yield per unit area than wheat and barley. In the 2014-2015 season, the corn production in Turkey was about 5.4 million tonnes and this number was expected to increase to 6.3 - 6.5 million tonnes in the coming 2015-2016 season. The driving force behind this recent increase primarily comes from the increased corn planting in the Southeastern Anatolia Region (Diyarbakır-Batman) and Central Anatolia Region (Konya-Karaman).

The increase in the yield of corn also greatly increases the contribution of this value added produce to the regional economies. As a highly competitive product, corn becomes advantageous in the Southeastern Anatolia Region compared to other grains and provides the farmers with the opportunity of a second harvest.

Corn with its extensive use for food, feed, and industrial products, especially biofuel ethanol, has resulted in the crop having the greatest volume of production of any cereal in the world [8]. Nowadays, there are over 4000 different products which have corn in its production whether directly or indirectly. The main areas of use for corn can be listed as; fresh (boiling and roasting ), canned, corn flour, starch, chips, oil, sweeteners, candy, gum, chocolate products, baby foods, salad dressings, alcohol, high fructose corn syrup, feed, toothpaste, ethanol (as gasoline additive) production, automotive industry, cleaning materials, textiles and cosmetics industries. It is estimated that of the world total production, $60 \%$ is used as animal feed, $20 \%$ as human food (direct consumption), $10 \%$ as processed food and $10 \%$ as seeds and other consumption. While the corn is mainly used for human consumption in developing countries, it is generally used for animal feed and as industry input in the developed countries. It is also a very important input for the Turkish animal husbandry sector.

In US, the most important corn producer in the world, of the 332 million tonnes of corn produced in $200748 \%$ was used as animal feed, $23 \%$ as ethanol, $4 \%$ as high fructose corn syrup, and $6 \%$ for other uses (starch, sweetener, alcohol, seed etc.) while the remaining 19\% was exported. On the other hand in 2002/03 these numbers were $59 \%$ for animal feed, $11.5 \%$ for ethanol and $17 \%$ for export. It can be easily seen from these numbers that corn is rapidly becoming a very important resource for the US industry, and especially for ethanol production.

Considering the rapid increase in number of GM constructs, more efficient and faster methods are needed to determine whether feeds and food contain approved or unapproved GM ingredients. Genetically modified constructs are often composed of common elements such as the 35S promoter, the NOS terminator or an antibiotic resistance gene as selection markers [9]. With the dramatic increase in the number and complexity of GM events with increased diversity of the introduced genetic elements, that can be present simultaneously in many products in the food and supply chain, testing directly for presence/absence of each and every genetically modified organism (GMO) is becoming extremely labour-intensive and costly [10]. The polymerase chain reaction (PCR) has proven to be the most accurate and reliable technique available for GMO detection, identification and quantification and is applicable to a wide range of samples, from seeds to highly processed food and feed. This technique is therefore widely used in GMO analysis. The PCR methods are generally grouped according to the specificity of the target sequence. The highest levels of specificity are achieved by event-specific methods that tar- 
get the junction between the inserted DNA and the recipient genome, as this region is unique to each DNA integration event [11]. Most of the GMO detection laboratories world over have started rationalizing their analytical work and now initially undertake poly-merase chain reaction (PCR)-based screenings followed by more specific identification and quantification assays (when appro-priate and required by the legislation) [10].

Mycotoxins are a diverse and ubiquitous group of compounds produced by fungal spores that are known to cause deleterious effects to the health of humans and animals. Viewed globally, food safety is regularly compromised by the presence of mycotoxins occurring in cereal grains, nuts, fruit and green coffee beans [12]. Aflatoxins (ATs) are fungal secondary toxic metabolites that naturally contaminate food and feed. They are produced by some Aspergillus moulds such as Aspergillus flavus, Aspergillus parasiticus and Aspergillus nomius [13].

There are four major aflatoxins named as $B_{1}, B_{2}, G_{1}$ and $G_{2}$. Among them, aflatoxin $B_{1}\left(A_{F B}\right)$ is classified as a carcinogenic substance of group 1 by the International Agency for Research on Cancer (IARC) as it may interfere the inductive of specific enzymes and forbid the synthesis of RNA [14]. In corn the fungus colonizes silk tissues, then grows down the silks to the kernels where it can infect developing kernels and go on to produce aflatoxins. Infection and colonization of tissues are facilitated when plants are stressed, for example by high temperature and drought [15].

Owing to the highly resistant to degradation to survive during food processing, $\mathrm{AFB}_{1}$ could enter the food chain and provide a threat to human health. Therefore, the regulatory limits for aflatoxins $\left(B_{1}+B_{2}+G_{1}+G_{2}\right)$, even for $\mathrm{AFB}_{1}$, have been established in several countries. The European Commission has set strict limits for the maximum allowed levels (MAL) of $\mathrm{AFB}_{1}$ in ground-nuts, dried fruits and their products, in which the MAL of $\mathrm{AFB}_{1}$ could not be greater than $2 \mu \mathrm{g} \cdot \mathrm{kg}^{-1}$ for Retail Ready Foods [14].

In this study the aflatoxin and GMO analyses of corn were made in two different years (2013 and 2014). Corn is one of the main inputs of both food and feed production. Agriculture of non-GMO corn is very important in Turkey because of the "Biosafety Law" No. 5977. With this study, the general situation in Turkey was shown in detail.

\section{Materials and Methods}

\subsection{Sampling}

Corn samples are collected by the following methods by SGS and Bureau Veritas laboratory firms, which are authorized in the analysis of GMOs and aflatoxin by the Turkey Ministry Food, Agriculture and Livestock, in accordance to specified rules so as to represent the country in general.

In August-October 2013 and 2014, corn samples were taken from gathered corn cobs that are harvested from nonadjacent fields in a way that is representative of every 10 thousand tonnes of corn harvested in Turkey. 538 and 517 corn samples were taken in 2013 and 2014, respectively.

In both years, as a representative for the country harvest in general, 1 sample was taken from the cobs that each represents a 10 thousand tonnes of harvest. Samples were taken from fields in 22 different counties that represent the country harvest in general. These counties are: Adana, Adıyaman, Amasya, Aydın, Bursa, Denizli, Diyarbakır, Gaziantep, Hatay, Iğdır, İzmir, Kahramanmaraş, Kırklareli, Konya, Manisa, Mardin, Mersin, Sakarya, Samsun, Şanlıurfa, Şırnak ve Tokat (Table 1).

In Turkey, corn is planted as the first crop in some counties and as the second crop in some others and is harvested in 2 different periods. While the harvest periods can change depending on the weather conditions, usually the first harvest happens in the beginning of August and the second in November. Depending on the rain fall, it lasts about a month and a half to two months. Harvest periods are listed below:

First harvest: August 5-September 10

Second harvest: November 9-November 30

In the previously mentioned years, the sample collection and analysis started in the beginning of August to be able to collect samples right before the harvest, and it finished with the collection of samples at the beginning of November from the fields that corn planted as the second crop. The list of counties where corn samples were collected in 2013 and 2014 are shown in Table 1 below.

In two years total of 1055 corn samples were analyzed. Each of the samples from the target regions were collected from 4 nonadjacent farms by taking a single cob from each that was at least 50 meters from the borders of the fields. Each of the cobs that would create the aggregate sample were first placed in 4 separate bags and then 
Table 1. Distribution of corn samples by counties.

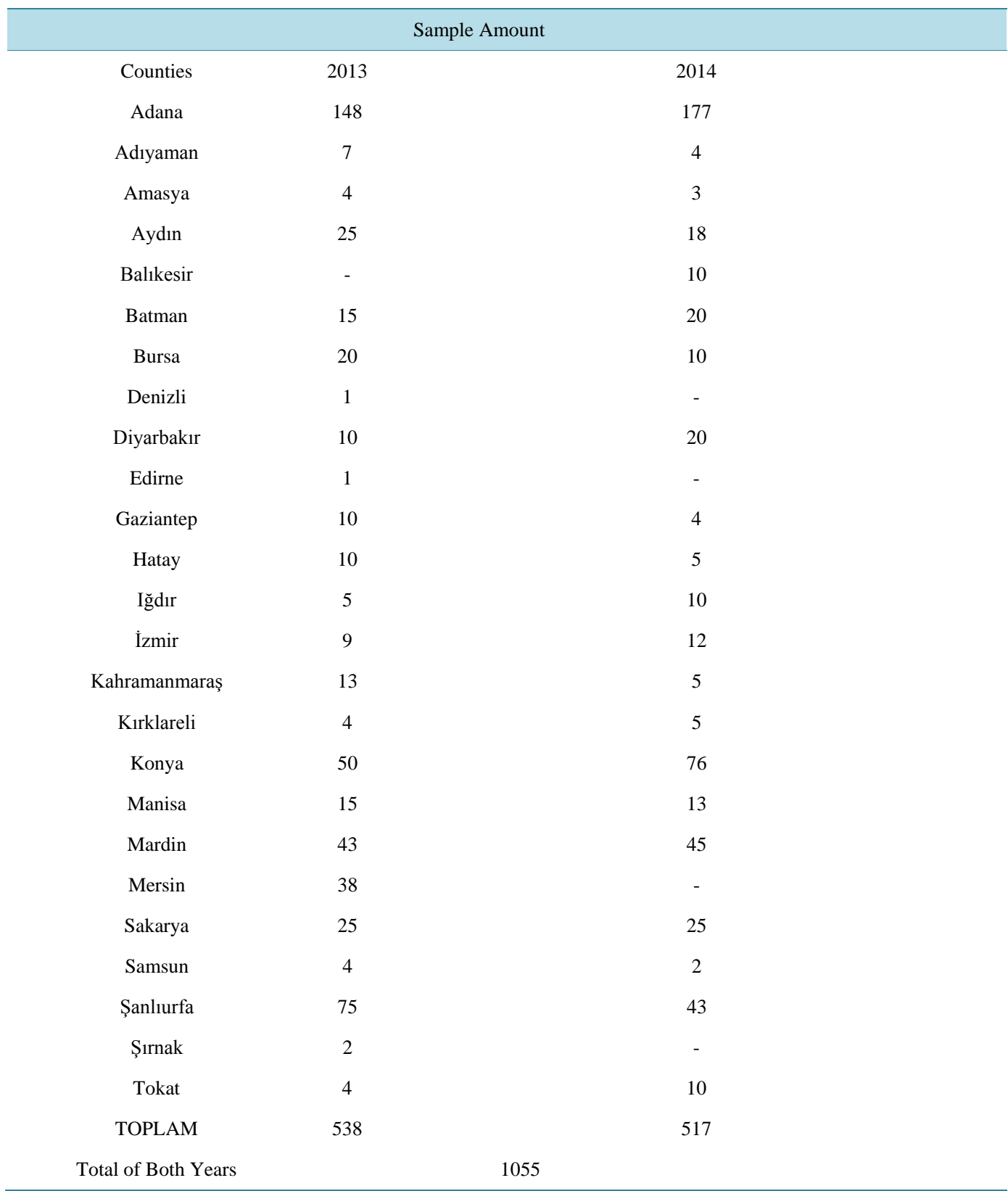

all 4 were bagged together, coded and transported to the labs in 2 days at the latest. The corn grains that were separated from 4 cobs in the laboratory were mixed and crushed into flour and then for the DNA isolation, 0.2 grams of samples were used from each sample groups.

Corn samples were taken before the first and second harvest periods from 22 corn producing counties in the country. Samples were taken from corn cobs grown in different fields by the teams of authorized accreditation institutions and were analyzed for GMO and aflatoxin.

\subsection{Instruments}

Homogenizer (GM200, Retsch), PC Cabinet (Escom), Precision Scale (Ohasus), Blender (Waring), Nano Photometer Pearl (Implen), Real-Time PCR System (Mx3005p Agilent), Refrigerated Centrifuge (Sigma), Plate Centrifuge (Sigma). 


\subsection{GMO Analysis}

GMO analysis is performed with the qualitative scanning of 35S promoter, NOS terminator, FMV promoter bar element gene parts (there is/isn't) $(0.01 \%$ precision). If the GMO analysis gives a positive result, further identification and quantification tests are conducted. Method used for the test is the R-Biopharm Sure Food Manual as defined in TS-EN ISO 24276, 2006. In Turkey, according to the "Biosafety Regulation” No 5977 the legal limit for GMOs is exactly 0 (zero). However there is an amendment to this regulation. Dated May 29, 2014 "The Regulation for Amending the Regulation of Genetically Modified Organisms and Products” No 20,914 defines "GMO Contamination" as accidentally transmitted GMOs or starting from the primary production, a product which is either genetically modified or not containing GMOs whose prevention is technically impossible. In the second clause of this regulation, a result of $0.9 \%$ or lower GMO content is defined as GMO contamination.

In this study, we used GMO Screen Kit (35S-NOS-FMV-IC) (Eurofins) and GENESpin DNA isolation kit (Eurofins). DNA/RNA free micropipette tips and microcentrifuge tubes were also used.

For DNA isolation, after heating to $65^{\circ} \mathrm{C} / 5 \mathrm{~min} 550 \mu \mathrm{L}$ Lysis Buffer is added to the $0.2 \mathrm{~g}$ corn sample and mixed for $0.5 \mathrm{~min}$ in vortex. Next, $10 \mu \mathrm{L}$ of Proteinase $\mathrm{K}\left(\mathrm{at}+4^{\circ} \mathrm{C}\right.$ ) was added and incubated in an agitator heater block at $65^{\circ} \mathrm{C}$ for 30 minutes while mixing at low speed. Following this step $10-20 \mu \mathrm{L}$ of RNaz $(20 \mathrm{mg} / \mathrm{mL})$ was added and incubated for 30 minutes at room temperature. After the incubation it was centrifuged for $10 \mathrm{mi}-$ nutes at $11.000 \mathrm{rpm}$ and supernatant was put into a $1.5 \mathrm{~mL}$ tube. Following this, Buffer C4 and ethanol (left in $45^{\circ} \mathrm{C}$ for $5 \mathrm{~min}$ ) added in at the same volume of supernatant taken and mixed in a vortex to ensure homogeneity. $650 \mu \mathrm{L}$ were then taken from the homogenous sample and GENESpin column was placed in, and then centrifuged at $11.000 \mathrm{rpm}$ for 1 minutes. This process was then repeated until the samples in the reaction tube depleted.

Same number of collection tubes was prepared as the samples. GENESpin column was placed in the prepared collection tubes and $400 \mu \mathrm{L}$ Buffer CQW added before centrifuging at $11.000 \mathrm{rpm}$ for 1 minute. After that GENESpin column was transferred to a new collection tube, $650 \mu \mathrm{L}$ Buffer C5 was added and centrifuged at $11.000 \mathrm{rpm}$ for 1 minute. After the centrifuge GENESpin column was again transferred to a new collection tube, $250 \mu \mathrm{L}$ Buffer C5 was added and centrifuged at $11.000 \mathrm{rpm}$ for 1 minute. After the centrifuge GENESpin column was transferred to $1.5 \mathrm{~mL}$ DNAse/RNAse free tubes and $100 \mu \mathrm{L}$ Buffer CE (heated up to $65^{\circ} \mathrm{C}$ ) added. After leaving in room temperature for 5 minutes it was then centrifuged at 11.000 rpm for 1 minutes, completing the DNA isolation process (Figure 1).

\subsubsection{DNA Amount and Purity Analysis}

For this purpose nanovolume spectrophotometer and Nanovolume Cuvette-Nucleic Asid-dsDNA mode were used. $2 \mu \mathrm{L}$ of Buffer CE was used as blank. By using Real Time PCR and $2 \mu \mathrm{L}$ sample according to the method specified in ISO 24276 (2006) DNA amount and purity were determined. The purity and concentration of the isolated DNA were determined with nanovolume spectrophotometer. In this way, we tried to prevent the incorrect measurement arising out of dilution. Optical Density (OD) of 1 ABS for double stranded DNA is $50 \mu \mathrm{g} / \mathrm{ml}$. For double stranded DNA the following formulae is used: DNA $(\mu \mathrm{g} / \mathrm{ml})=$ OD at $260 \mathrm{~nm}$ (Absorbance value) $\mathrm{x}$ Dilution Rate $\mathrm{x} 50$ (amount and purity of DNA was determined through values gathered by the spectrophotometer at 260 and 280 nm wavelengths). For the purity of DNA A (260/280) and B (260/230) values were examined. Because, DNA peaks at 260, protein at 280 and RNA at $230 \mathrm{~nm}$ wavelengths. In a pure DNA sample, a value (260/280) is expected to be near the $1.80-2.00$ range. A value below 1.8 points to protein contamination and above 2.0 points to RNA contamination.

\subsubsection{Controlling Plant DNA}

If the result of the spectrophotometric measurements reveals very low amounts of DNA presence, it is necessary to examine the plant DNA. To determine the existence of the plant DNA, region of the plant DNA is increased by using primer sequences from the gene regions specific to the plant, and the presence of this increase is measured with Syber Green Method b using Real Time PCR. For determining nonspecific increases, melting curve analysis is conducted. For the reaction, the following primer sequences belonging to the plant chloroplast are used:

Forward Primer: 5’CGAAATCGGTAGACGCTACG 3'

Reverse Primer: 5’GGGGATAGAGGGACTTGAAC 3' 


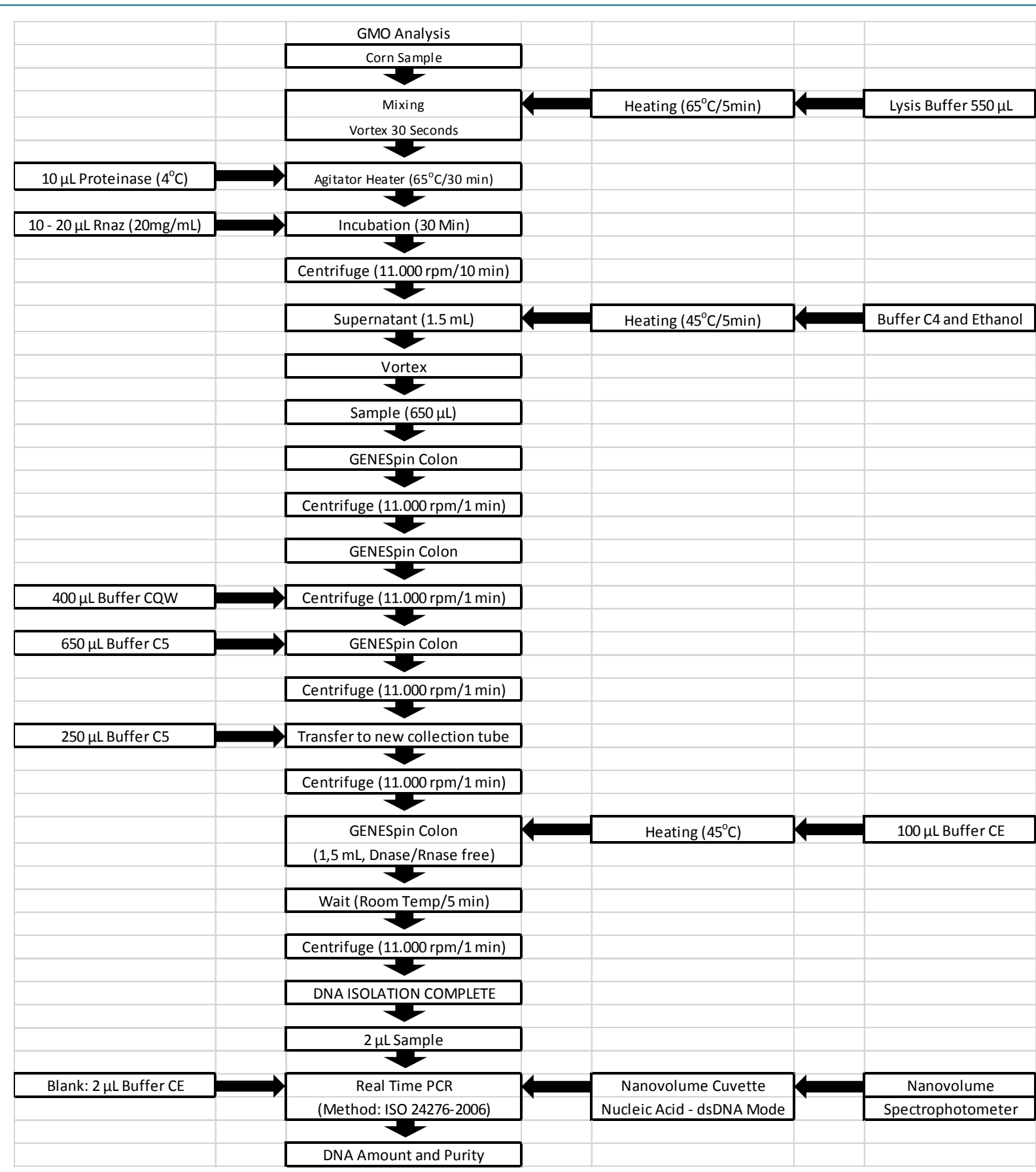

Figure 1. GMO analysis flowchart.

\subsection{Aflatoxin Analysis}

Aflatoxin $\left(B_{1}, B_{2}, G_{1}\right.$ and $\left.G_{2}\right)$ analysis in corn samples were done through AOAC. 991.31 (2010) method by using LC-MS/MS technique. The legal limit of aflatoxin in foods for B1 is 5 ppb (parts per billion) and for total aflatoxin is $10 \mathrm{ppb}$ (Figure 2).

\subsubsection{Extraction}

$25 \mathrm{~g}$ samples were weighed from the corn samples and inserted into the receptacle of the crusher. Then, after adding $5 \mathrm{~g}$ of sodium chloride and $125 \mathrm{~mL}$ of extraction solution it was homogenized in a mixer at high speed 


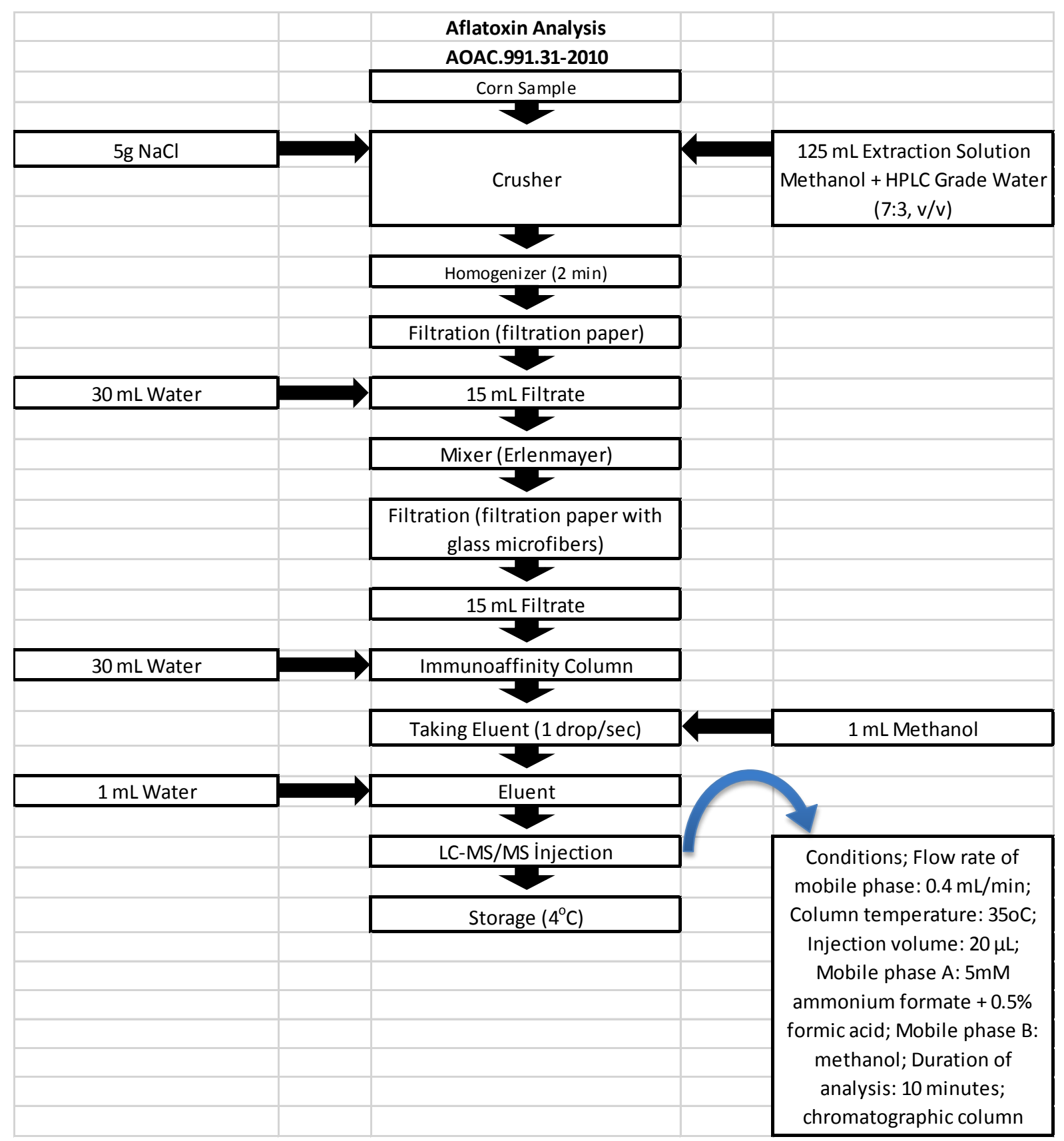

Figure 2. Aflatoxin analysis flowchart.

for 2 minutes. Methanol + HPLC grade water (7:3) (v/v) was used as the extraction solution. Mixture was then filtered through a folded filter. $15 \mathrm{~mL}$ of filtrate was then drawn with a suitable pipette and transferred to an Erlenmeyer with a lid. After that, $30 \mathrm{~mL}$ of water was added and mixed after closing the lid of the Erlenmeyer. Before starting the affinity column chromatography, diluted extract was filtered through a filtration paper with glass microfibers until it became clear. Then the immunoaffinity column process was started.

\subsubsection{Column Process}

A $10 \mathrm{~mL}$ disposable syringe was attached above the immunoaffinity column which contains special antibodies for aflatoxin $B_{1}, B_{2}, G_{1}$ and $G_{2}$. Then column solution was poured into the immunoaffinity column. $15 \mathrm{~mL}$ of prepared filtrate was then taken into the syringe. During the immunoaffinity process 1 - 2 drops/second flow was 
maintained. For cleaning the column, $10 \mathrm{~mL}$ of water was passed through twice at a suitable speed. To acquire the aflatoxin $\left(B_{1}, B_{2}, G_{1}\right.$ and $\left.G_{2}\right)$ eluent inside the column $1 \mathrm{~mL}$ of methanol was dripped at a 1 drop/second rate. After that eluent was gathered and $1 \mathrm{~mL}$ of water was added in. After mixing thoroughly, eluent was drawn with a pipette into a vial and the HPLC injection was completed.

\subsubsection{HPLC Analysis}

The following were chosen as the HPLC working conditions; mobile phase flow rate: $0.4 \mathrm{ml} / \mathrm{min}$; column temperature: 35C; injection volume: $20 \mu \mathrm{l}$; mobile phase A: $5 \mathrm{mM}$ ammonium formate $+0.5 \%$ formic acid; mobile phase B: methanol; Analysis time: $10 \mathrm{~min}$; chromatographic column: SB-C18 (3.0 × $100 \mathrm{~mm} 3.5 \mathrm{um})$.

\subsection{Statistical Analysis}

Statistical analyses were performed using MINITAB-15 (Minitab Inc., State College, PA) and MSTAT statistical packages (Michigan State University, East Lansing, MI). Values with $\mathrm{P}<0.05$ were considered significant.

\section{Results and Discussion}

In the study, corn samples were collected between August and October in 2013 and 2014 around Turkey from non-neighboring fields representing each 10 thousand tons production and blending. 538 samples were taken in 2013 and 517 samples in 2014.

Samples were collected from fields in 22 cities representing the corn harvest of Turkey. These cities are Adana, Adiyaman, Amasya, Aydin, Bursa, Denizli, Diyarbakir, Gaziantep, Hatay, Igdir, Izmir, Kahramanmaras, Kirklareli, Konya, Manisa, Mardin, Mersin, Sakarya, Samsun, Sanliurfa, Sirnak and Tokat.

\subsection{Aflatoxin Levels in Corn}

Aflatoxin, which is one of the most important quality criteria of corn and a major concern during harvest and storage, can be decreased with informed agriculture techniques and education.

Aflatoxin levels varied among 1055 samples from different regions depending on the conditions. Cities with aflatoxin containing samples were given in Table 2.

After the analyses, 38 of 538 corn samples (7.06\%) were found to contain aflatoxin in 2013. 17 of these were collected from the first harvest, 21 were from the second harvest period. The city with highest aflatoxin was Sanliurfa with 19 samples. Adana followed Sanliurfa with 8 samples from second harvest containing aflatoxin Table 2). Only 2 of 517 corn samples (0.38\%) analyzed in 2014 were found to contain aflatoxin. Origins of these two samples were Adiyaman and Manisa.

Information on aflatoxin levels in 2013 were given in Table 3. In 2013, samples from 10 regions contained aflatoxins. In 3 of these regions only second harvest samples were found positive. Data on aflatoxin levels in 2014 were given in Table 4. Aflatoxin limits were exceeded in samples from only 2 regions in 2014.

Most important causes for aflatoxin occurrence are the conditions before harvest as well as the processes during and after harvesting. Pre-harvest aflatoxin occurrence can be minimized by planting suitable to weather conditions, and correct irrigation. Preventing aflatoxin during and after harvest can be achieved with use of proper harvest techniques, appropriate drying and storage of corn grains. One of the two important precautions is preventing mechanical grain damage that provides suitable conditions for mold growth. The second one is drying of the grains to a level that will not allow mold growth, again without damaging the grains. It is utterly important to bring grains rapidly to drying process, dry each grain effectively, use conveyors, elevators and storage equipment that will not damage the grains and keep them at the correct moisture levels, in order to prevent aflatoxin production. These facts are recently considered important in Turkish agriculture, hence aflatoxin levels decreased and it became possible to produce safe food and feed.

With the help of studies, processes like GLOBAL GAP, GAP and GMP and risk evaluation, aflatoxin levels dropped from $7.06 \%$ in 2013 to $0.38 \%$ in 2014 . This decrease was related mainly to climate conditions, but also to factors like stress resistance of the seeds, crop stress on the field, appropriate irrigation and agriculture practices and sowing densities.

\subsection{GMO Screening Test}

The legal limit for GMO in food is 0 (zero) according the Biosafety Law No. 5977. But a revision was made on 
Table 2. Samples from around Turkey containing aflatoxin.

\begin{tabular}{|c|c|c|c|c|c|c|}
\hline & & 2013 & & & 2014 & \\
\hline & Number of Samples & First Harvest & Second Harvest & Number of Samples & First Harvest & Second Harvest \\
\hline Adana & 148 & - & 8 & 177 & - & - \\
\hline Adiyaman & 7 & 1 & - & 4 & 1 & - \\
\hline Amasya & 4 & - & - & 3 & - & - \\
\hline Aydin & 25 & 1 & - & 18 & - & - \\
\hline Balikesir & - & - & - & 10 & - & - \\
\hline Batman & 15 & - & - & 20 & - & - \\
\hline Bursa & 20 & - & - & 10 & - & - \\
\hline Denizli & 1 & 1 & - & - & - & - \\
\hline Diyarbakir & 10 & 3 & - & 20 & - & - \\
\hline Edirne & 1 & - & - & - & - & - \\
\hline Gaziantep & 10 & - & - & 4 & - & - \\
\hline Hatay & 10 & 1 & - & 5 & - & - \\
\hline Igdir & 5 & - & - & 10 & - & - \\
\hline Izmir & 9 & - & - & 12 & - & - \\
\hline Kahramanmaras & 13 & - & - & 5 & - & - \\
\hline Kirklareli & 4 & - & - & 5 & - & - \\
\hline Konya & 50 & - & - & 76 & - & - \\
\hline Manisa & 15 & - & - & 13 & 1 & - \\
\hline Mardin & 43 & - & 1 & 45 & - & - \\
\hline Mersin & 38 & 2 & - & - & - & - \\
\hline Sakarya & 25 & - & - & 25 & - & - \\
\hline Samsun & 4 & - & - & 2 & - & - \\
\hline Sanliurfa & 75 & 8 & 11 & 43 & - & - \\
\hline Sirnak & 2 & - & 1 & - & - & - \\
\hline Tokat & 4 & - & - & 10 & - & - \\
\hline \multirow[t]{2}{*}{ Total } & 538 & 17 & 21 & 517 & 2 & - \\
\hline & \multicolumn{5}{|c|}{38} & 2 \\
\hline
\end{tabular}

Table 3. Aflatoxin levels of corn samples in 2013.

\begin{tabular}{ccccccc}
\hline Samples with Aflatoxin & & Aflatoxin $\mathrm{B}_{1}(\mu / \mathrm{kg})$ & & \multicolumn{2}{c}{ Total Aflatoxin $(\mu / \mathrm{kg})$} \\
\hline $\mathrm{n}=38$ & Minimum & Maximum & Average & Minimum & Maximum & Average \\
& 7.01 & 160.75 & 49.73 & 7.96 & 163.62 \\
\hline
\end{tabular}

Table 4. Aflatoxin levels of corn samples 2014.

\begin{tabular}{|c|c|c|c|c|c|c|}
\hline \multirow{3}{*}{$\begin{array}{l}\text { Samples with Aflatoxin } \\
\qquad \mathrm{n}=2\end{array}$} & \multicolumn{3}{|c|}{ Aflatoxin $B_{1}(\mu / \mathrm{kg})$} & \multicolumn{3}{|c|}{ Total Aflatoxin $(\mu / \mathrm{kg})$} \\
\hline & Minimum & Maximum & Average & Minimum & Maximum & Average \\
\hline & 21.22 & 25.59 & 23.40 & 22.19 & 26.06 & 24.2 \\
\hline
\end{tabular}


May 29, 2014 with the regulation No. 20,914 “Change in the Regulation Regarding Genetically Modified Organisms and Products”. In the revision, GMO contamination was defined as technically unpreventable, unavoidable or incidental contamination of a genetically modified or non-modified product on every production step starting from the initial production. The second article of the regulation states that "an analysis result indicating $0.9 \%$ or less GMO in a product is considered as GMO contamination".

According to the analyses made in 2013-2014 on corn samples from 22 different cities, no GMO were detected. This result shows that the Biosafety Law is enforced properly. Moreover, courses on preventing the risk of contamination contributed to the successful result and their continuance were shown to be beneficial.

Usage of non-GMO corn in food and feed production is highly important in Turkey. In GMO screening tests 25S Promoter, NOS Terminator and FMV Promoter were sought. None of the samples showed a positive result. This means that the 538 samples in 2013 and 517 samples in 2014 were all non-GMO (data not shown). GMO screening tests in both years had $0.05 \%$ analysis sensitivity level.

\section{Conclusions}

There have been many important developments in recent years in Turkey, and these developments lead to considerable progress in growing aflatoxin-free and non-GMO corn. Use of non-GMO corn in food and feed production is important in Turkey. This study also reports results of GMO screening tests with $0.05 \%$ detection limit in two marketing years. 35D promoter, NOS terminator and FMV promoter are sought with the tests. None of the samples shows positive results, that is, samples do not contain GMO. Looking at these results, one may conclude that presence of corn as the raw material for food and feed stuff suited for the demands of consumers is very important in terms food security. These results indicate accordance to the Biosafety Law No. 5977 and Food Regulation No. 5996.

According to these results, 6.5 million tons of non-GMO corn have filled our silos this season, to be used in food and feed industries. This is an important outcome of a years-long effort and shows that Turkey has become self-sufficient in terms of corn and food security.

\section{References}

[1] Silva, F., Braga, M. and Garcia, J. (2015) Link Between R\&D Intensity and Market Concentration: Analysis of Brazilian Corn and Soybean Seed Markets. 2015 Conference, International Association of Agricultural Economists, 9-14 August 2015, Milan, 1-26.

[2] Rubio, F., Guo, E. and Kamp, L. (2014) Survey of Glyphosate Residues in Honey, Corn and Soy Products. Journal of Environmental \& Analytical Toxicology, 4, 2161-0525.

[3] Sönmezoğlu, Ö.A. and Keskin, H. (2015) Determination of Genetically Modified Corn and Soy in Processed Food Products. Journal of Applied Biology \& Biotechnology, 3, 032-037. http://dx.doi.org/10.7324/JABB.2015.3307

[4] Phelps, R.L. (2015) Testing USDA Certified Organic and Non-GMO Verified Project Labeled Foods for the Presence of Genetic Modifications. Masters Theses \& Specialist Projects, Paper 1548. http://digitalcommons.wku.edu/theses/1548

[5] Goodwin, B.K., Marra, M. and Piggott, N. (2014) The Cost of a GMO-Free Market Basket of Food in the US. http://www4.ncsu.edu/ bkgoodwi/papers/non_gmo.pdf

[6] Santa-Maria, M.C., Lajo-Morgan, G. and Guardia, L. (2014) Adventitious Presence of Transgenic Events in the Maize Supply Chain in Peru: A Case Study. Food Control, 41, 96-101. http://dx.doi.org/10.1016/j.foodcont.2014.01.006

[7] Sawazaki, H.E., Duarte, A.P., Fuzatto, M.G., Sawazaki, E., Grandi, S.H.R., de Ponte, J.F. and Nogueira, L. (2015) Identification and Quantification of Corn, Soybean and Cotton Genetically Modified by Real Time PCR. American Journal of Molecular Biology, 5, 84. http://dx.doi.org/10.4236/ajmb.2015.53007

[8] Bruns, H.A. (2015) Ear Leaf Photosynthesis and Related Parameters of Transgenic and Non-GMO Maize Hybrids. International Journal of Agronomy, 2015, Article ID: 731351. http://dx.doi.org/10.1155/2015/731351

[9] Rayan, A.M., Nigussie, F. and Abbott, L.C. (2015) Safety Evaluation of Stacked Genetically Modified Corn Event (MON89034 × MON88017) Using Zebrafish as an Animal Model. Food and Nutrition Sciences, 6, 1285. http://dx.doi.org/10.4236/fns.2015.614134

[10] Randhawa, G.J., Morisset, D., Singh, M. and Žel, J. (2014) GMO Matrix: A Cost-Effective Approach for Screening Unauthorized Genetically Modified Events in India. Food Control, 38, 124-129.

http://dx.doi.org/10.1016/j.foodcont.2013.10.013 
[11] Angers-Loustau, A., Petrillo, M., Bonfini, L., Gatto, F., Rosa, S., Patak, A. and Kreysa, J. (2014) JRC GMO-Matrix: A Web Application to Support Genetically Modified Organisms Detection Strategies. BMC Bioinformatics, $15,417$. http://dx.doi.org/10.1186/s12859-014-0417-8

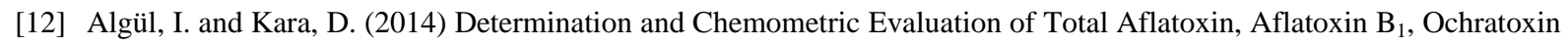
A and Heavy Metals Content in Corn Flours from Turkey. Food Chemistry, 157, 70-76. http://dx.doi.org/10.1016/j.foodchem.2014.02.004

[13] Abdel-Azeem, S.M., Diab, M.A. and El-Shahat, M.F. (2015) Ultra-High-Pressure Liquid Chromatography-Solid-Phase Clean-Up for Determining Aflatoxins in Egyptian Food Commodities. Journal of Food Composition and Analysis, 44, 18-24. http://dx.doi.org/10.1016/j.jfca.2015.06.005

[14] Zhang, X., Li, C.R., Wang, W.C., Xue, J., Huang, Y.L., Yang, X. X., Qiu, J.F., et al. (2016) A Novel Electrochemical İmmunosensor for Highly Sensitive Detection of Aflatoxin $\mathrm{B}_{1}$ in Corn Using Single-Walled Carbon Nanotubes/ Chitosan. Food Chemistry, 192, 197-202. http://dx.doi.org/10.1016/j.foodchem.2015.06.044

[15] Accinelli, C., Abbas, H.K., Vicari, A. and Shier, W.T. (2014) Aflatoxin Contamination of Corn Under Different AgroEnvironmental Conditions and Biocontrol Applications. Crop Protection, 63, 9-14.

http://dx.doi.org/10.1016/j.cropro.2014.04.021 